\title{
Variabilidade genética em populações de campo do nematóide de cisto da soja provenientes dos estados do Paraná e Rio Grande do Sul
}

\author{
Hamilton Santana ${ }^{1}$, Ely Pires ${ }^{1}$, Anna P. Comerlato ${ }^{2}$, Erica G.C. Nasu² \& Cleber Furlanetto ${ }^{3}$ \\ ${ }^{1}$ Cooperativa Central de Pesquisa Agrícola, 85.813-450 Cascavel, PR, Brasil; ${ }^{2}$ Laboratório de Nematologia, Universidade \\ Estadual do Oeste do Paraná - UNIOESTE, 85.960-000, Marechal Cândido Rondon, PR, Brasil; ${ }^{3}$ Departamento de \\ Fitopatologia, Universidade de Brasília, 70.910-000, Brasília, DF, Brasil
}

Autor para correspondência: Cleber Furlanetto, e-mail: cfurla@hotmail.com

\section{RESUMO}

Este estudo objetivou conhecer a variabilidade genética em populações do nematóide de cisto da soja (NCS), Heterodera glycines, utilizando para inoculação das diferenciadoras populações monocísticas e policísticas. Cistos de H. glycines foram extraídos de amostras de solo coletadas em plantações de soja dos municípios de Cruz Alta RS e Porto Mendes PR e em Novo Horizonte PR, distrito de Marechal Cândido Rondon, com posterior inoculação de ovos e J2 nas diferenciadoras. A reação das diferenciadoras frente ao inóculo policístico permitiu a identificação apenas da raça prevalecente ou em maior população dentro de cada amostra coletada, tendo sido detectada apenas a raça 3 na amostra de Cruz Alta e somente a raça 6 na amostra de Porto Mendes. Porém, não foi possível identificar a raça prevalecente de H. glycines para a amostra de Novo Horizonte. Contudo, quando se estudou a variabilidade genética do NCS dentro de cada amostra, utilizando-se inóculo oriundo da multiplicação de cistos individuais, observou-se a ocorrência das raças 6 e 3 na amostra de Cruz Alta, raças 6, 5 e 2 para Porto Mendes e raças 10 e 6 para Novo Horizonte. Portanto, o processo monocístico permitiu antever a evolução populacional das raças nas amostras do NCS estudadas.

Palavras-chave: Heterodera glycines, hospedeiros diferenciadores, isolados monocísticos, isolados policísticos.

\begin{abstract}
Genetic variability in field populations of the soybean cyst nematode from the states of Paraná and Rio Grande do Sul, Brazil

This work aimed to study the genetic variability in populations of the soybean cyst nematode (SCN), Heterodera glycines, using polycystic and monocystic populations for inoculation on differential hosts. Cysts of $H$. glycines were extracted from soil samples collected in soybean plantations from the counties of Cruz Alta RS and Porto Mendes PR and from Novo Horizonte PR, district of Marechal Cândido Rondon, with further inoculation of eggs and J2 on differential hosts. The differential host reaction, using polycystic inoculum, allowed only the identification of the prevalent race or the race with highest population within each sample. In the sample of Cruz Alta only race 3 was detected and in the sample of Porto Mendes only race 6 . However, it was not possible to identify the prevalent race of $H$. glycines in the sample of Novo Horizonte. Nevertheless, when the genetic variability of SCN was studied within each population, using inoculum from populations built up from single cysts, races 6 and 3 were detected in the sample of Cruz Alta, races 6, 5 and 2 from Porto Mendes and races 10 and 6 from Novo Horizonte. Therefore, the monocystic process allowed to know the race diversity in the samples studied.
\end{abstract}

Keywords: Heterodera glycines, differential hosts, monocystic isolates, polycystic isolates.

A reprodução anfimítica, aliada à copulação por mais de um macho (Triantaphyllou \& Esbenshade, 1990), resulta em grande variabilidade genética dentro de populações de campo do nematóide de cisto da soja (NCS). Essa variabilidade pode ser caracterizada por meio de uma série diferenciadora composta por genótipos de soja (Golden et al., 1970), definindo-se assim raças fisiológicas. Até 16 raças podem ser caracterizadas pelo esquema proposto por Riggs \& Schmitt (1988). Uma outra forma de caracterizar esta variabilidade é classificar as populações de $H$. glycines em tipos, como recentemente proposto por Niblack et al. (2002).

O uso de cultivares de soja resistentes constitui um sistema de manejo de $H$. glycines no campo (Franzener et al., 2005). A maioria das cultivares comerciais de soja disponíveis no Brasil é resistente apenas às raças 1 e 3 do NCS. Entretanto, a variabilidade do patógeno pode levar à perda da resistência quando a cultivar é plantada em monocultura (Almeida et al., 2005; Dias et al., 2007). A caracterização desta variabilidade é ferramenta muito útil 
para os melhoristas de soja, na definição de estratégias para o desenvolvimento de cultivares resistentes, e também para os produtores, na seleção de genótipos para semeadura em áreas infestadas. Dessa forma, objetivou-se neste trabalho, estudar a variabilidade genética de três populações de $H$. glycines, coletadas em lavouras de soja dos estados do PR e RS, a partir da identificação de raças em culturas policísticas e monocísticas.

As populações do NCS utilizadas nesse estudo foram obtidas a partir de três amostras de solo enviadas ao laboratório de Nematologia da UNIOESTE, em Marechal Cândido Rondon PR. Uma amostra era oriunda do município de Cruz Alta RS e as outras duas de Novo Horizonte PR, distrito de Marechal Cândido Rondon, e Porto Mendes PR. Populações policísticas e isolados monocísticos foram multiplicados em plantas de soja da cultivar CD 202, cultivadas em tubetes plásticos de $20 \times 5 \mathrm{~cm}$, contendo 200 $\mathrm{g}$ de substrato estéril formado pela mistura de solo e areia (1:1). Durante o período de condução do ensaio, os tubetes foram mantidos em recipientes de $20 \mathrm{~L}$ com areia estéril, os quais foram depositados em cuba metálica com água e temperatura variando de $25-28^{\circ} \mathrm{C}$.

Para a extração dos cistos e a obtenção de isolados monocísticos e populações policísticas, $200 \mathrm{cc}$ de solo infestado das amostras de campo, foram homogeneizados em recipiente contendo cerca de 10 litros de água e a suspensão passada, em seqüência, pelas peneiras de 20 e 60 mesh. O material retido na peneira de 60 mesh foi recolhido em béquer e passado através de papel de filtro. Para a obtenção de isolados monocísticos, ovos foram extraídos de cistos individuais e isolados policísticos foram obtidos a partir de 50 cistos viáveis. Os isolados monocísticos e as populações policísticas foram multiplicados por três gerações em soja CD 202, para a obtenção de inóculo suficiente para a inoculação da série diferenciadora de raças do NCS. Fêmeas e cistos de $H$. glycines foram extraídos de raízes de plantas de soja com jatos fortes de água e macerados em um conjunto de peneiras de 60 mesh e 400 mesh. Posteriormente, os ovos e J2 foram recolhidos da peneira de 400 mesh para um béquer e quantificados em lâmina de Peters, calibrando-se a suspensão de inóculo para 1.000 ovos e $\mathrm{J} 2 \mathrm{~mL}^{-1}$, para inoculação das plantas diferenciadoras.

Para determinação das raças de $H$. glycines, utilizouse a série diferenciadora de genótipos de soja proposta por Golden et al. (1970), com os genótipos Pickett, Peking, PI 88788, PI 90763 e mais Lee (padrão de suscetibilidade) e Hartwig (padrão de resistência). Cada planta de soja foi inoculada no estádio V1 com $5.000 \mathrm{~J} 2$ e ovos. Os ensaios foram conduzidos em casa-de-vegetação e seguiram o delineamento inteiramente casualisado com cinco repetições. Aos 30 dias após a inoculação, fêmeas de $H$. glycines foram extraídas e quantificadas por sistema radicular de soja. Para o cálculo do Índice de Fêmeas (IF), foi utilizada a equação: $\mathrm{IF}=$ Média de fêmeas (MF) na diferenciadora/ MF em Lee X 100. Considerou-se como reação positiva
$(+)$, aquela aonde o número de fêmeas foi superior ou igual a $10 \%$ daquela observada na cultivar Lee e negativa (-), quando esse número foi inferior a $10 \%$ na mesma cultivar. Nas amostras de solo infestado, coletadas em plantações de soja dos municípios de Cruz Alta RS e Porto Mendes PR, a determinação da raça de $H$. glycines empregando-se 50 cistos (policísticas) permitiu a caracterização apenas da raça 3 (Cruz Alta RS) e da raça 6 (Porto Mendes PR) (Tabela 1). Problemas na multiplicação do inóculo procedente de Novo Horizonte (PR), impossibilitou a caracterização da raça nessa amostra.

Quando se estudou a variabilidade genética do NCS, obtendo-se o inóculo a partir da multiplicação de apenas um cisto, detectaram-se as raças 6 e 3 (Cruz Alta, RS), raças 6, 5 e 2 (Porto Mendes, PR) e 10 e 6 (Novo Horizonte, $\mathrm{PR})$, com maior freqüência das raças 3, 6 e 10 dentre os isolados de Cruz Alta, Porto Mendes e Novo Horizonte, respectivamente (Tabela 2).

A variabilidade genética encontrada na amostra de Cruz Alta RS, com prevalência da raça 3 sobre a raça 6 de H. glycines, aliada a relatos anteriores para o estado do Rio Grande do Sul, indica uma provável prevalência das raças 3 e 6 nessa região, mas em níveis populacionais variáveis. A raça 3 de $H$. glycines foi relatada anteriormente nos municípios gaúchos de São Miguel das Missões, Coimbra e Cruzeiro do Sul (Bonato et al., 2002; Dias et al., 2006), enquanto a raça 6 foi relatada somente em Cruzeiro do Sul (Wain \& Silva, 1998; Dias et al., 2006). A raça 3 de $H$. glycines foi relatada também nos municípios de Sertaneja (Wain \& Silva, 1998; Dias et al., 2006), Congonhinhas e Bela Vista do Paraíso, norte do Paraná, e em municípios do oeste paranaense como Tupãssi e Marechal Cândido Rondon (Dias et al., 2006). No entanto, para Novo Horizonte, distrito de Marechal Cândido Rondon, e Porto Mendes, ambos localizados no oeste paranaense, foram detectadas as raças 2, 5, 6 e 10 em níveis populacionais diferentes e ausência da raça 3 (Tabela 2). Portanto, a determinação da raça do NCS a partir de populações policísticas detecta apenas a raça em maior população dentro da amostra advinda do campo. Já a análise monocística, permite antever o processo de evolução populacional das raças dentro da amostra. Assim, pode-se inferir sobre raças potenciais para a plantação de soja em questão.

Foram constatadas dinâmicas diferentes na evolução das raças minoritárias dentro das populações do NCS estudadas. Enquanto em Porto Mendes PR ocorreram duas raças minoritárias (5 e 2), em Cruz Alta RS e Novo Horizonte PR constatou-se a presença apenas da raça 6 como minoritária. Essa variação gênica nas populações do nematóide pode ter sido motivada pela diferença na origem dos genes de resistência das cultivares de soja utilizadas anteriormente em cada uma das áreas.

Isolados monocísticos multiplicados na cv. Lee 68 foram utilizados por Dong et al. (2005), para a determinação das freqüências alélicas em três populações de campo de H. glycines. Em uma população de campo originalmente 

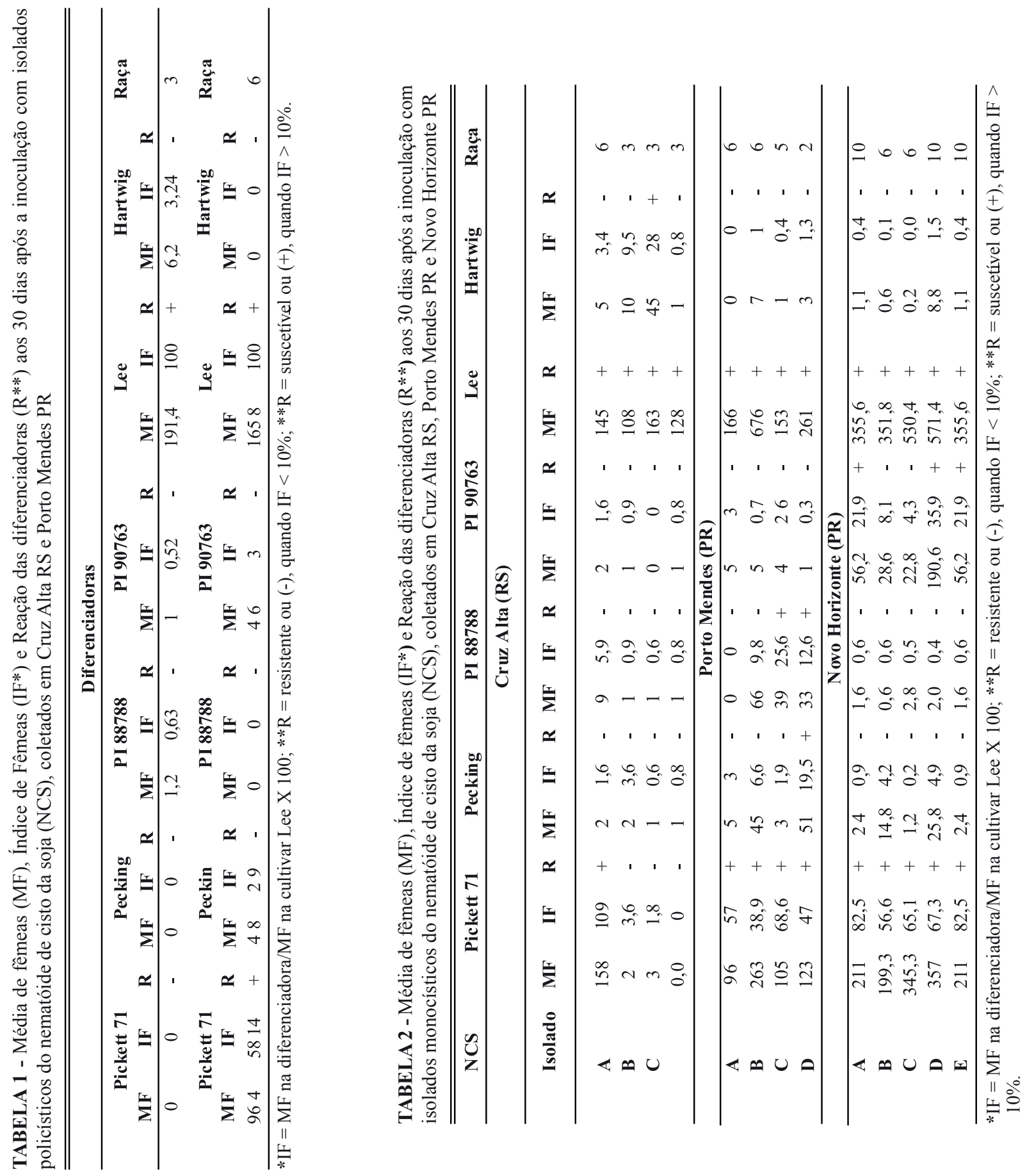
identificada como raça 3 pelo processo policístico, isolados monocísticos deram origem às raças $1(20 \%), 3(73,3 \%)$ e 6 $(6,67 \%)$. Em uma segunda população (raça 5), detectaramse as raças $2(13,33 \%), 5(66,7 \%), 6(6,67 \%)$ e $9(13,33 \%)$. Finalmente, isolados monocísticos de uma terceira população (raça 14), deram origem às raças $6(53,33 \%), 9(13,33 \%)$ e $14(33,33 \%)$. Por outro lado, embora o cultivo de cistos individuais em vasos permita inferir sobre a variabilidade genética presente em campo, testes in vitro com inóculo obtido a partir de cistos individuais pode auxiliar na seleção de genótipos resistentes, como demonstrado por Brown (1976) para genótipos de trigo.

Realmente as populações de $H$. glycines apresentam variações quantitativas em suas composições gênicas. Portanto, ao longo do tempo pode ocorrer mudança na raça fisiológica prevalecente pela elevação da freqüência da raça capaz de multiplicar na cultivar de soja resistente cultivada na área (Triantaphyllou, 1975a, b; Schmitt \& Noel, 1984). A pressão de seleção exercida pela monocultura da cultivar de soja resistente, resulta na seleção de outras raças. Dias et al. (1998) relataram a "quebra" de resistência da cv. Hartwig, anteriormente resistente a todas as raças de $H$. glycines, por uma população de campo coletada em Sorriso MT e denominada de raça $4^{+}$. Colgrove et al. (2002) relataram alterações a campo na freqüência gênica de $H$. glycines, provocadas pelo plantio de cultivares de soja resistentes ao NCS, mesmo quando utilizadas em rotação com o milho.

O conhecimento prévio das raças em evolução dentro de uma população de campo do NCS é importante para auxiliar o produtor na seleção de cultivares resistentes para plantios futuros na área e, também, para direcionar os trabalhos dos melhoristas para a obtenção de novas cultivares resistentes. Contudo, o uso de culturas monocísticas para a determinação de raças do NCS, quando comparado com o processo policístico, é laborioso, demanda tempo e apresenta custos mais altos.

\section{REFERÊNCIAS BIBLIOGRÁFICAS}

Almeida AMR, Ferreira LP, Yorinori JT, Silva JFV, Henning AA, Godoy CV, Costamilan LM, Meyer MC (2005) Doenças da soja (Glycine max). In: Kimati H, Amorim L, Rezende JAM, Bergamim Filho A, Camargo LEA (Eds.) Manual de Fitopatologia. Vol. 2. Doenças das plantas cultivadas. $4^{\text {a }}$ ed. Piracicaba SP. Editora Ceres. pp. 569-588.

Bonato ER, Costamilan LM, Ferreira Filho A, Silva JFV, Bertagnolli PF (2002) Distribuição do nematóide de cisto da soja
(Heterodera glycines Ichinohe, 1952) no Rio Grande do Sul. Nematologia Brasileira 26:97-100.

Brown JAM (1976) Breeding for resistance to cereal cyst nematode in wheat II. Use of test tube cultures in selection. Euphytica 26:8995.

Colgrove AC, Smith GS, Wrather JA, Heinz RD, Niblack TL (2002) Lack of predictable race shift in Heterodera glycines field plots in Missouri. Plant Disease 86:1101-1108.

Dias WP, Silva JFV, Garcia A, Carneiro GES (2006) Nematóides de importância para a soja no Brasil. In: Suzuki S, Yuyama MM, Camacho AS (Eds.) Boletim de Pesquisa de Soja No. 10, Fundação Mato Grosso, Rondonópolis MT. Editora Central de Textos. pp. 139-151.

Dias WP, Silva JFV, Kiihl RAS, Hiromoto DM, Abdelnoor RV (1998) Quebra de resistência da cv. Hartwig por população de campo do nematóide de cisto da soja (Heterodera glycines). Pesquisa Agropecuária Brasileira 33:971-974.

Dong K, Barker KR, Opperman CH. (2005) Virulence genes in Heterodera glycines: allele frequencies and Ror gene groups among field isolates and inbred lines. Phytopathology 95:186191.

Franzener G, Unfried JR, Stangarlin JR, Furlanetto C (2005) Nematóides formadores de galha e de cisto patogênicos à cultura da soja em municípios do oeste do Paraná. Nematologia Brasileira 29:261-265.

Golden AM, Epps JM, Riggs RD (1970) Terminology and identity of intraspecific forms of soybean cyst nematodes (Heterodera glycines). Plant Disease Reporter 54:544-546.

Niblack TL, Arelli PR, Noel GR, Opperman CH, Orf JH, Schmitt DP, Shannon JG, Tylka GL (2002) A revised classification scheme for genetically diverse populations of Heterodera glycines. Journal of Nematology 34:279-288

Riggs RD, Schmitt DP (1988) Complete characterization of the race scheme for Heterodera glycines. Journal of Nematology 20:392-395

Schmitt DP, Noel GR (1984) Nematodes parasites of soybean. In: Nickle WR (Ed.) Plant and insect nematodes. New York NY. Marcel Dekker. pp. 13-59.

Triantaphyllou AC (1975a) Genetic structure of races of Heterodera glycines and inheritance of ability to reproduce on resistant soybeans. Journal of Nematology 7:356-364.

Triantaphyllou AC (1975b). Oogenesis and the chromosomes of twelve bisexual species of Heterodera (Nematoda: Heteroderidae). Journal of Nematology 7:34-40.

Triantaphyllou AC, Esbenshade PR (1990) Demonstration of multiple mating in Heterodera glycines with biochemical markers. Journal of Nematology 22:452-456.

Wain AL, Silva JFV (1998) Levantamento de raças de Heterodera glycines no Brasil. Nematologia Brasileira 22: 82-85. 